\title{
Infratentorial hygroma secondary to decompressive craniectomy after cerebellar infarction
}

\author{
S. Tejada-Solís; R. Díez-Valle; P.D. Domínguez-Echavarri*; M.R. García de Eulate-Ruiz* y A. Gómez-Ibáñez**
}

Departamentos de Neurocirugía, Radiología* y Neurología**. Clínica Universitaria de Navarra.

\section{Summary}

We present a case of expansive CSF collection in the cerebellar convexity. The patient was a 74 years old lady who one month before had suffered a cerebellar infarct complicated with acute hydrocephalus. She had good evolution after decompressive craniectomy without shunting. Fifteen days after surgery, the patient started with new positional vertigo, nausea and vomiting and a wound CSF fistula that needed ventriculoperitoneal shunt (medium pressure) because conservative treatment failed. After shunting, the fistula closed, but the patient symptoms worsened. The MRI showed normal ventricular size with a cerebellar hygroma, extending to the posterior interhemispheric fissure. The collection had no blood signal and expanded during observation. A catheter was implanted in the collection and connected to the shunt. The patient became asymptomatic after surgery, and the hygromas had disappeared in control CT at one month.

This case shows an infrequent problem of CSF circulation at posterior fossa that resulted in vertigo of central origin. A higroma-ventricle-peritoneal shunt solved the symptoms of the patient.

KEY WORDS: Central vertigo. Infratentorial hygroma. Posterior fossa decompression.

Higroma infratentorial secundario a una craniectomía descompresiva tras un infarto de cerebelo

\section{Resumen}

Presentamos el caso de una paciente con una colección expansiva de LCR sobre la convexidad del cerebelo. La paciente, de 74 años de edad, había sido intervenida de urgencia un mes antes por un infarto de hemisferio cerebeloso e hidrocefalia aguda, con buena evolución tras la craniectomía descompresiva de fosa posterior y

Recibido: 25-11-08. Aceptado; 20-12-08 sin necesitar válvula. A los 15 días de la intervención, la paciente comenzó con un cuadro de vértigo posicional, náuseas, vómitos y una fístula de LCR, que al no responder al tratamiento conservador fue tratada con una válvula VP de presión media. Tras implantar la válvula la fístula se cerró, pero el cuadro clínico de la paciente empeoró.

En una resonancia magnética se objetivó un tamaño ventricular normal e higromas infratentoriales que se extendían hacia la fisura interhemisférica posterior. En los higromas no se objetivó señal de sangrado y fueron aumentando de tamaño. Se implantó un catéter a nivel del higroma de mayor tamaño en la fosa posterior y se conectó a la válvula que portaba la paciente, evolucionando de forma favorable clínica y radiológicamente. Al mes de la intervención los higromas habían desaparecido en el TAC de control.

Este caso muestra una situación infrecuente de alteración del flujo de LCR a nivel de la fosa posterior que da lugar a un cuadro de vértigo de origen central. EI drenaje de los higromas, mediante un catéter conectado a una válvula ventriculo peritoneal, solucionó la sintomatología.

PALABRAS CLAVE: Vértigo central. Higroma infratentorial. Descompresión fosa posterior.

Introduction

Subdural CSF collections in cerebellar convexity are very unusual and have been reported as cause of cerebellar syndromes 5 . Only a few cases have been described, none following a decompressive craniectomy. The appearance of a pathological cavity in the central nervous system after a surgery or a trauma could originate disturbances of CSF circulation.

Case report

A 74 years old woman presented dizziness, nausea and vomiting for 24 hours and was admitted in our hospital 


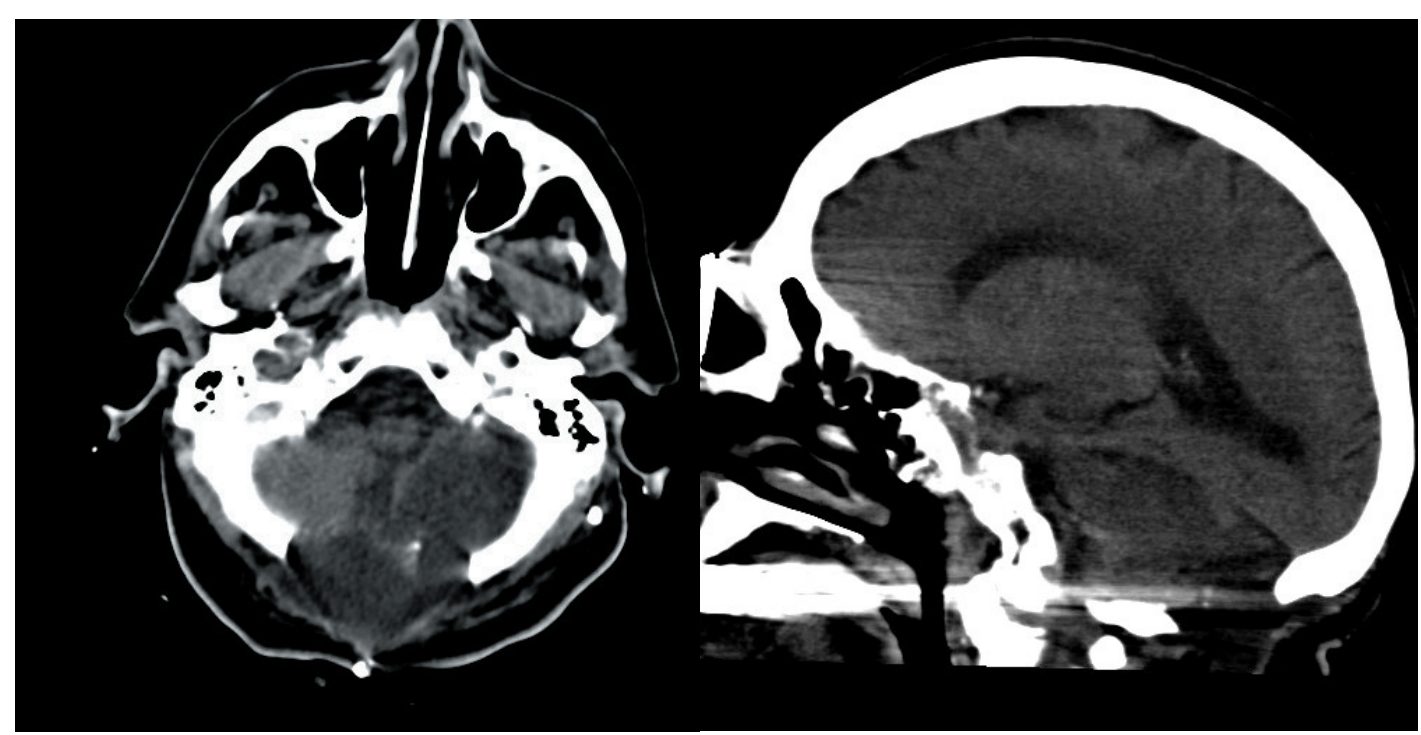

Figure 1. The $C T$ scan shows a hemispheric cerebellar infarction with important mass effect and hydrocephalus.

Figure 2. A control CT scan shows normal ventricular size and a collection where the cerebellar infarction had occurred. The pseudomeningocele persisted.

somnolent. A CT scan showed a hemispheric cerebellar infarction with important mass effect and hydrocephalus (Fig. 1).

The conscience level was worsening, so a decompressive posterior fossa craniectomy was made. She recovered, and did not need a shunt in that moment. She was discharged in 7 days, ambulatory, without dizziness. After 15 days she came back to the hospital because a CSF fistula, and she had started having dizziness again, specially with movements, however no nistagmus, dysmetria, nor ataxia were present.

A lumbar drainage resolved temporary the fistula, although, when the drainage was closed the fistula reopened. We implanted a ventriculoperitoneal shunt, medium pressure, and the fistula closed definitely. A control CT scan showed a pseudomeningocele and a collection where the cerebellar infarction had occurred with normal ventricular size (Fig. 2).
After the shunt was implanted, the patient symptoms got worse slowly in weeks, with severe vertigo, nausea and vomiting associated with upright position and movements, but not when she was at bed. Nistagmus but no dysmetria nor ataxia was present. Neurologists and ENT made an exhaustive study and peripheral vertigo and other neurological problems were excluded. An MRI one month after showed big bilateral hygromas in the cerebellum convexity, extending to the posterior interhemispheric fissure (Fig. 3).

The collection had no blood signal and caused big mass effect over posterior fossa structures with an incipient medullar deformity. The patient received medical treatment with steroids and acetazolamide and got better for two weeks. After the improvement, she started worsening again, and a ventricular catheter was implanted in the biggest hygroma of posterior cranial fossa and connected to the shunt with a Y-shape connector. Two 


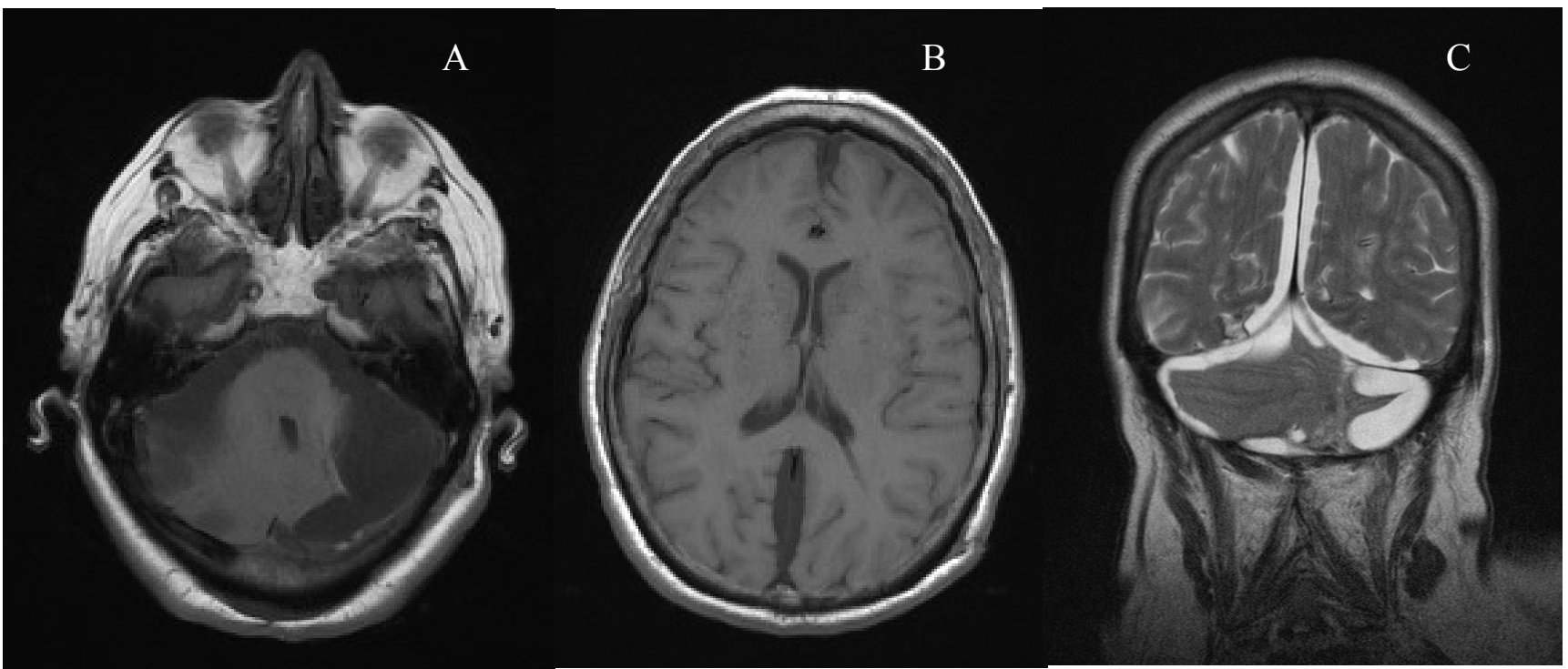

Figure 3: An MRI (A: T1 axial, supratentorial; B: T1 axial infratentorial; C: T2 coronal) one month after the shunting shows big bilateral hygromas over the cerebellum convexity, extending to the posterior interhemispheric fissure.

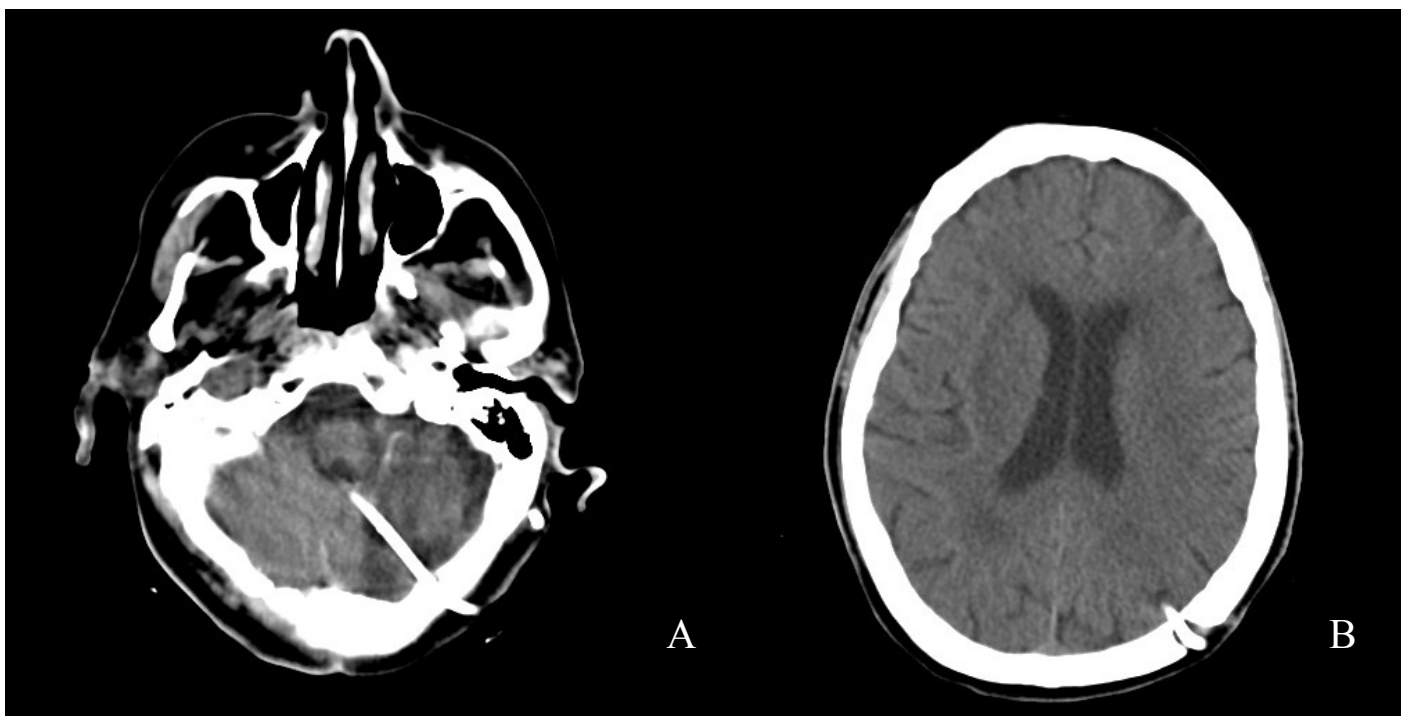

Figure 4: In the control CT scan at one month after surgery the hygromas have disappeared, the patient was asymptomatic. $4 A$ shows the catheter implanted in the infratentorial higroma. $4 B$ present the resolution of the supratentorial higromas.

days after the surgery the patient was asymptomatic and the hygromas had disappeared in the control CT scan at one month (Fig. 4).

\section{Discussion}

There is not an easy explanation for the fluid accumulation and the high pressure in the posterior fossa in this case. The imaging sequence clearly shows there is an expanding accumulation and not an ex-vacuo collection. The vertigo of the initial cerebellar infarction had clearly resolved and there were no other signs of a new ischemia to explain the clinical worsening, the clinical symptoms were typical of an expanding mass. The MRI and CT scan did not show any signs of blood products like a subdural chronic hema- toma to explain this collection.

After the cerebellar infarction and the subsequent decompressive craniectomy a disruption in the CSF dynamics occurred with liquid getting out of the fourth ventricle into the subdural space and with a flap-valve effect. The clinical timing suggest the fluid was leaking from the arachnoid causing the fistula first, after the fistula closed, the CSF followed the subdural plane, the pressure increased and the patient got worse. The CSF accumulated in the subdural space of the posterior fossa and continued to dissect through the tentorial notch into the supratentorial compartment. We cannot explain why the ventricular catheter did not avoid the high pressure in the posterior fossa, and why the CSF produced in the ventricles could travel forward those compartments, but not go back. We can 
speculate some valve mechanism was formed. A catheter placed in the posterior fossa hygroma and spliced into the existing valve system established the equilibrium needed, with total disappearance of the abnormal collection. The symptoms disappeared quickly with the drainage of the fluid collection, which confirms that in this case, the mass effect and the clinical worsening was due to expanding hygromas in the posterior cranial fossa. This technique had been published before with the same good result ${ }^{3}$.

Up to date six cases of symptomatic subdural hygromas in adults have been reported by different authors ${ }^{1,2,4,5}$, all of them secondary to posterior fossa decompression. Five patients were treated for Chiari malformation Type I (CMI) and one patient presented a hemangioblastoma ${ }^{5}$. All the CM-I cases resolved spontaneously; the authors of these reports explain the formation of the hygromas following a pinhole arachnoid tear during durotomy that formed the basis of the valve mechanism. Nevertheless, the arachnoid was widely opened during the hemangioblastoma surgery and our case of cerebellar infarction surgery. These two cases have in common that both presented cerebellar symptoms, have pseudomeningocele and needed a new surgery for solving the symptoms. These could suggest that the bigger arachnoidal gaps provided more fluid getting out and dissecting to the subdural space, causing more severe symptoms. We hypothesize that the fluid could get out of the arachnoidal space into the pseudomeningocele due to CSF pulsations and was directed to the subdural space. Because the presence of some mechanical valve system, the fluid accumulated in the subdural space instead of going back. This mechanical valve system could be formed between the injured parenchyma and the dura mater. Although the shunt was working, it could not solve the hygromas.

\section{Conclusion}

Subdural hygromas in the posterior fossa can be symptomatic and not always resolve spontaneously. Dra- inage through a shunt system could be useful in similar situations. The pathophysiology of the CSF is complex and our knowledge can not already explain every pathological situation. One way communication between different cranial compartments could play a role in the dynamics of some CSF disorders, and therefore need separate draining.

\section{References}

1. Arrese, I., Kaen, A., Lobato, R.D.: Infratentorial hygroma. J Neurosurg 2006; 104: 856-857; author reply 857.

2. Marshman, L.A., Benjamin, J.C., Chawda, S.J., David, K.M.: Acute obstructive hydrocephalus associated with infratentorial subdural hygromas complicating Chiari malformation Type I decompression. Report of two cases and literature review. J Neurosurg 2005; 103: 752-755.

3. Nadkarni, T.D., Rekate, H.L.: Treatment of refractory intracranial hypertension in a spina bifida patient by a concurrent ventricular and cisterna magna-to-peritoneal shunt. Childs Nerv Syst 2005; 21: 579-582.

4. Ranjan, A., Cast, I.P.: Symptomatic subdural hygroma as a complication of foramen magnum decompression for hindbrain herniation (Arnold-Chiari deformity). Br J Neurosurg 1996; 10: 301-303.

5. Stavrinos, N.G., Taylor, R., Rowe, A., Whittle, I.R.: Posterior fossa surgery complicated by a pseudomeningocele, bilateral subdural hygromata and cerebellar cognitive affective syndrome. Br J Neurosurg 2008; 22: 107-109.

Tejada-Solís, S.; Díez-Valle, R.; Domínguez, P.D.; García De Eulate-Ruiz, M.R.; Gómez-Ibáñez, A.: Infratentorial hygroma secondary to decompressive craniectomy after cerebellar infarction. Neurocirugía 2009; 20: 470-473.

Correspondencia postal: Sonia Tejada Solís. Departamento de Neurocirugía. Clínica Universitaria de Navarra. Avenida Pío XII, 36. 31008 Pamplona (Navarra). 